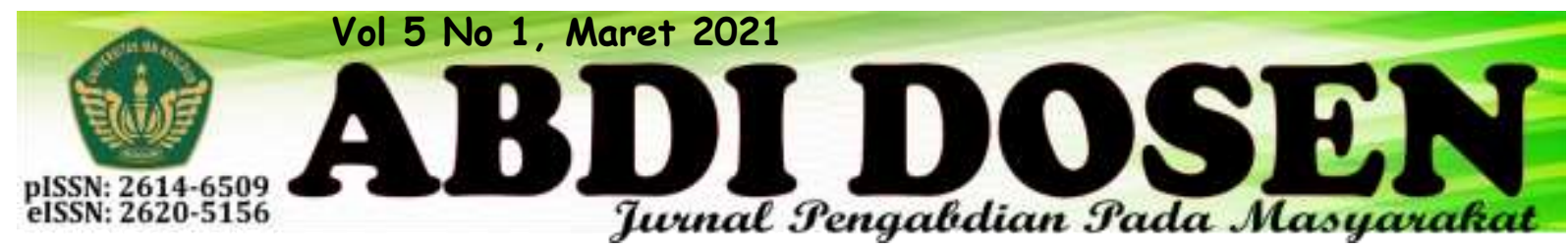

\title{
ETIKA BERBICARA DALAM KELUARGA \\ BERSAMA RADIO 93.0 RESPON FM RADIONYA KELURAGA ANDA
}

\author{
Firdaus $^{1}$, Dini Susanti ${ }^{2}$, Vini Wela Septiana ${ }^{3}$, Ismail Syakban ${ }^{4}$, Thaheransyah ${ }^{5}$, Syaflin Halim ${ }^{6}$ \\ firdaushisab@gmail.com ${ }^{1}$ \\ dinisusanti35@gmail.com ${ }^{2}$ \\ viniwela86@gmail.com ${ }^{3}$ \\ ismail.syakban@gmail.com ${ }^{4}$ \\ thaherumsb@gmail.com ${ }^{5}$ \\ syaflinhalim26@gmail.com ${ }^{6}$ \\ Fakultas Agama Islam Universitas Muhammadiyah Sumatera Barat 1,2,3,4,5,6
}

\begin{abstract}
ABSTRAK
Keluarga adalah lingkungan sosial terkecil di dalam masyarakat dimana setiap anggotanya terikat oleh hubungan pernikahan dan darah. Dalam konteks pendidikan, keluarga adalah lingkungan utama yang pertama kalinya memberikan bekal pendidikan kepada anak dalam berbagai aspek kehidupan, terutama dalam hal pendidikan sosial- kemasyarakatan. Pendidikan dalam keluarga yang paling utama adalah dalam hal membentuk akhlak anak-anak sebagai bekal mereka dalam menghadapi kehidupannya kelak. Setiap keluarga, khususnya keluarga muslim, kedua orangtua tentu saja berharap anak-anak mereka memiliki akhlak yang baik (akhlakul karimah). Dalam hal ini, pola komunikasi dalam hal ini merupakan etika berbicara dalam keluarga memegang peranan yang sangat penting. Etika berbicara yang baik, menggabungkan antara komunikasi verbal dan non verbal, komunikasi individu dan kelompok, ikut menentukan bagaimana akhlak seorang anak dibentuk. Subjek dalam pengabdian ini merupakan para pendengar Radio 93,0 Respon FM. Dengan pemilihan subjek ini, karena Radio ini mempunyai program yang sangat bagus yaitu tentang keluarga. Maka dipilihlah radio ini. Pendekatan yang dilakukan melalui Radio 93,0 Respon FM ini pendengar terutama untuk warga /masyarakat Kasang Kab. Padang Pariaman agar bisa memahami hubungan baik dalam keluarga. Proses kegiatan ini yang diawali dengan Penyampaian materi, mendemonstrasikan, dan tanya jawab secara langsung.
\end{abstract}

\section{Kata Kunci : Keluaraga, Komunikasi, Etika Berbicara}

\section{PENDAHULUAN}

a. Isu dan Focus Penelitian

Komunikasi adalah suatu aktivitas manusia yang saling berinteraksi antara satu oarang maupun lebih, di dalam pandangan agama islam komunikasi memiliki etika, agar jika kita melakukan komunikasi dengan seseorang maka orang itu dapat memahami apa yang kita sampaikan. Etika adalah cabang utama filsafat yang mempelajari nilai atau kualitas yang menjadi studi mengenai standar dan penilaian moral. Etika mencakup analisis dan penerapan konsep seperti benar, salah, baik, buruk, dan tanggung jawab.

Keluarga adalah salah satu kelompok atau kumpulan manusia yang hidup bersama sebagai satu kesatuan atau unit 
masyarakat terkecil dan biasanya selalu ada hubungan darah, ikatan perkawinan atau ikatan lainnya, tinggal bersama dalam satu rumah yang dipimpin oleh seorang kepala keluarga dan makan dalam satu periuk.

Pentingnya etika dalam sebuah keluarga dilihat dari berbagai aspek. Meski setiap keluarga memiliki etika atau aturan yang berbeda-beda. Itu semua terjadi karena adanya perbedaan pandangan dan pendapat yang terbentuk oleh lingkungan.

\section{b. Alasan Memilih Subjek}

Alasan memilih menggunakan Radio 93,0 Respon FM agar warga / masyarakat Kasang Kab. Padang Pariaman bisa mendengar dari rumah masing-masing keluarga. penjelasan tentang etika berbicara dalam

\section{c. Tujuan Kegiatan}

Berdasarkan masalah yang ada maka kegiatan ini bertujuan :

1. Memberikan pengetahuan tentang komunikasi dan interaksi dalam keluarga

2. Menggunakan etika dalam keluarga terutama dari aspek berbicara

\section{d. Kegunaan Kegiatan}

Kegiatan berguna untuk :

1. Menambah pengetahuan pendengar yang ada dirumah melalui radio khususnya masyarakat Kasang Kab. Padang Pariaman tentang etika berbicara dalam keluarga. Karena Radio 93,0 Respon FM adalah radioanya keluarga anda, khusus membahas tentang keluarga.

2. Menambah poin bagi tim pengabdian kepada masyarakat menuju status fungsional dan kenaikan pangkat/golongan.

\section{KERANGKA TEORITIS}

\section{a. Pengertian Etika}

Menurut bahasa Yunani Kuno, etika berasal dari kata ethikos yang berarti "timbul dari kebiasaan". Etika adalah cabang utama filsafat yang mempelajari nilai atau kualitas yang menjadi studi mengenai standar dan penilaian moral. Etika mencakup analisis dan penerapan konsep seperti benar, salah, baik, buruk, dan tanggung jawab.

Etika biasanya berkaitan erat dengan perkataan moral yang berarti juga adat kebiasaan atau cara hidup seseorang dengan melakukan perbuatan yang baik (kesusilaan), dan menghin-dari hal-hal tindakan yang buruk.Etika dan moral lebih kurang sama pengertiannya, tetapi dalam kegiatan sehari-hari terdapat perbedaan, yaitu moral atau moralitas untuk penilaian perbuatan yang dilakukan, sedangkan etika adalah untuk pengkajian sistem nilai-nilai yang berlaku.

Kata etika seringkali disebut pula dengan kata etik, atau ethics (bahasa Inggris), mengandung banyak pengertian. Dari segi etimologi (asal kata), istilah etika berasal dari kata Latin "Ethicos" yang berarti kebiasaan. Dengan demikian menurut pengertian yang asli, yang dikatakan baik itu apabila sesuai dengan kebiasaan masyarakat. Kemudian lambat laun pengertian ini berubah, bahwa etika adalah suatu ilmu yang mebicarakanmasalah perbuatan atau tingkah laku manusia, mana yang dapat dinilai baik dan mana yang dapat dinilai tidak baik.

Etika juga disebut ilmu normative, 
maka dengan sendirinya berisi ketentuanketentuan (norma-norma) dan nilai- nilai yang dapat digunakan dalam kehidupan sehari-hari. Dalam kamus besar bahasa Indonesia terbitan Departemen Pendidikan dan Kebudayaan (1988), etika dirumuskan dalam tiga arti, yaitu;

1) Ilmu tentang apa yang baik dan apa yang buruk dan tentang hak dan kewajiban moral (akhlak).

2) Kumpulan asas atau nilai yang berkenaan dengan akhlak.

3) Nilai mengenai benar dan salah yang dianut suatu golongan atau masyarakat.

\section{b. Pengertian Keluarga}

Keluarga adalah salah satu kelompok atau kumpulan manusia yang hidup bersama sebagai satu kesatuan atau unit masyarakat terkecil dan biasanya selalu ada hubungan darah, ikatan perkawinan atau ikatan lainnya, tinggal bersama dalam satu rumah yang dipimpin oleh seorang kepala keluarga dan makan dalam satu periuk. Suatu keluarga setidaknya memiliki ciri-ciri sebagai berikut:

1) Terdiri dari orang-orang yang memiliki ikatan darah atau adopsi.

2) Anggota suatu keluarga biasanya hidup bersama-sama dalam satu rumah dan mereka membentuk satu rumah tangga.

3) Memiliki satu kesatuan orang-orang yang berinteraksi dan saling berkomunikasi, yang memainkan peran suami dan istri, bapak dan ibu, anak dan saudara.

Mempertahankan suatu kebudayaan bersama yang sebagian besar berasal dari kebudayaan umum yang lebih luas.

\section{c. Etika Dalam Keluarga}

Dalam sebuah keluarga biasanya terdiri dari beberapa anggota yaitu, ayah, ibu, dan anak. Masing-masing anggota dalam keluarga memiliki etika masingmasing yang bisa dijadikan pedoman. Diantaranya:

\section{1) Etika suami Istri}

Hak-hak ini, sebagian sama di antara suami-istri dan sebagiannya tidak sama. Hak-hak yang sama di antara suarni-istri adalah sebagian berikut:

a) Masing-masing suami-istri harus bersikap amanah terhadap pasangannya, dan tidak mengkhianatinya sedikit atau banyak, karena suami istri adalah laksana dua mitra di mana pada keduanya harus ada sifat amanah, saling menasihati, jujur, dan ikhlas dalam semua urusan pribadi keduanya, dan urusan umum keduanya.

b) Masing-masing suami-istri harus memberikan cinta kasih yang tulus kepada pasangannya sepanjang hidupnya

c) Masing-masing suami-istri harus mempercayai pasangannya, dan tidak boleh meragukan kejujurannya, nasihatnya, dan keikhlasannya.

\section{2) Etika Anak Terhadap orang Tua}

Seorang anak harus menghormati orang tua, berbakti kepada orang tua dan taat pada orang tua. Karna orang tua kita telah melahirkan, membesarkan kita dari kecil hngga dewasa yang penuh kasih saying. Bahkan orang tua kita sudah memberikan segala-galanya tanpa pamrih kepada ank-anaknya tanpa mengharapkan imbalan dari anaknya. Orang tua menyayangi anaknya melebihi dirinya.

Kewajiban seorang anak hanya membalasnya dengan tingkah dan sikap 
anak yang baik terhadap orang tua, membahagiakan atau membanggakan orang tua melalui prestasi dan keberhasilan anak. Orang tua bukan berarti hanya kedua orang tua yang melahirkan kita. Tetapi orang tua yang dimaksud disini adalah orang yang lebih tua dari kita haruslah bersikap baik dengannya. Selain kewajiban anak terhadap orang tua, anak juga mempunyai hak terhadap orang tua, yaitu: mendapatkan kasih sayang, perhatian, bimbingan dan kehidupan yang layak.

\section{3) Etika Berbicara dalam Kelurga}

Dalam kehidupan sehari-hari bahasa digunakan untuk berkomunikasi baik itu verbal ataupun non verbal. Lazimnya berbahasa zaman sekarang yaitu bicara memakai mata tapi jari jemari berkata-kata dalam artian mulutnya diam. Kualitas seseorang dalam berkata-kata menunjukkan eksistensinya dalam berkepribadian. Dan itu tidak bisa di nilai kecuali oleh orang yang berinteraksi langsung dengan yang bersangkutan, baik dia itu handal dalam bertulisan ataupun jago berbicara di media dan tidak akan menjamin bicaranya sesuai dengan apa yang dia tulis.

Setiap manusia telah di bekali lisan oleh Yang Maha Kuasa untuk berbicara dan bertutur kata, tujuannya adalah berbicara yang baik-baik saja, adapun yang buruk dalam berbicara/berbahasa kembali pada pribadi masing-masing. Dalam hal ini norma dan kesopanan menjadi prioritas utama dan pertama ketika berinteraksi dengan individu atau kelompok. Etika berbicara rasanya tidak terlalu formal jika di artikan sederhana karena bukan seperti berpidato, artinya ketika berbicara kita harus mengetahui lawan bicara kita, apakah pantas di bicarakan, apakah tidak? Sehingga tidak norak dan kampungan. Intinya lebih kepada orang atau individu yang berbicaranya, yaitu manusianya itu yang mengendalikan bucaranya sediri.

Dalam berbicara kita juga tentu harus bisa membedakan, mana yang muda, mana yang tua, mana yang seumuran, mana yang tidak seumuran. Kesannya terlalu egois tapi memang itu etikanya. Dan sudah mendarah daging serta membudaya di negara kita. Dalam hal tulis menulis kita juga sedang berbicara, beretika atau tidak tergantung sejauh mana kita berinteraksi dengan sesama profesi dengan cukup baik dan berlatih bicara baik juga. Tidak ada yang instan di dunia ini, termasuk dalam hal etika berbicara karena menyeduh mie instan saja perlu waktu walau hanya beberapa menit saja maka berlatihlah untuk beretika dalam berbicara.

Untuk memberikan teladan kesantunan pada anak, ada beberapa prinsip kesantunan yang perlu diperhatikan orang tua. Berikut ini prinsip-prinsip kesantunan berbahasa yang diterapkan di keluarga.

1. Maksim Kebijaksanaan

Maksim ini menggariskan setiap peserta pertuturan untuk meminimalkan kerugian orang lain, atau memaksimalkan keuntungan bagi orang lain. Maksim Kedermawanan

Maksim ini mewajibkan setiap peserta tindak tutur untuk memaksimalkan kerugian bagi diri sendiri, dan meminimalkan keuntungan bagi diri sendiri.

2. Maksim Penghargaan

Maksim penghargaan diutarakan dengan kalimat asertif dan kalimat ekspresif. Maksim penghargaan menuntut setiap peserta pertuturan untuk memaksimalkan rasa hormat kepada orang lain, dan meminimalkan rasa tidak hormat 
kepada orang lain.

Maksim Kesederhanaan Maksim ini menuntut setiap peserta pertuturan untuk memaksimalkan ketidakhormatan pada diri sendiri dan meminimalkan rasa hormat pada diri sendiri. Maksim Kemufakatan

Maksim ini menggariskan setiap penutur dan lawan tutur untuk memaksimalkan kecocokan di antara mereka, dan meminimalkan ketidakcocokan di antara mereka.

3. Maksim Simpati

Maksim ini mengharuskan setiap peserta pertuturan untuk memaksimalkan rasa simpati, dan meminimalkan rasa antipati kepada lawan tuturnya.

Catatan: Maksim adalah Pernyataan ringkas yang mengandung ajaran atau kebenaran umum tentang sifatsifat manusia; aforisme; peribahasa.

\section{4) Penggunaan kesantunan linguistik tuturan imperatif dalam Rumah}

\section{Tangga}

Orang tua sering menggunakan tuturan perintah/imperatif kepada anak. Penggunaan kesantunan linguistik tuturan imperatif oleh Orang tua perlu memperhatian kesantunan dalam penggunaan tuturan imperatif. Penggunaan kesantunan linguistik orang tua kepada anak di rumah, merupakan salah satu contoh upaya menanamkan kesantunan bahasa bagi anak. Pembiasaan kesantunan bahasa kepada anak dengan memberikan teladan bahasa yang santun oleh orang tua merupakan langkah yang tepat. Beberapa langkah dapat dilakukan orang tua untuk menciptakan tuturan yang santun.
1. Penggunaan tuturan yang panjang Semakin panjang tuturan yang digunakan, akan semakin santunlah tuturan itu. Sebaliknya, semakin pendek sebuah tuturan, akan cenderung semakin tidak santunlah tuturan itu. Panjang pendek tuturan berhubungan sangat erat dengan masalah kelangsungan dan ketidaklangsungan dalam bertutur.

2. Penggunaan urutan tuturan

Hymes menyampaikan bahwa konsep mnomonik "SPEAKING", dalam teori etnografi komunikasi, bahwa urutan tutur (acts sequence) menentukan makna sebuah tuturan. Sebuah tuturan yang sebelumnya kurang santun dapat menjadi santun ketika tuturan itu ditata kembali urutannya. Penataan ulang tuturan berpengaruh terhadap maksud yang ingin disampaikan. Dengan demikian, urutan sebuah tuturan ikut mempengaruhi kesantunan sebuah tuturan.

3. Intonasi dan isyarat-isyarat

kinestetik

Menurut Sunaryati intonasi adalah tinggi rendah suara, panjang-pendek suara, keras-lemah suara, jeda, irama, dan timbre yang menyertai tuturan. Penggunaan intonasi pada tuturan turut berperan dalam menciptakan kesantunan sebuah tuturan imperatif. Selain intonasi, kesantunan penggunaan tuturan imperatif dalam bahasa Indonesia juga dipengaruhi oleh isyarat-isyarat kinestetik yang dimunculkan melalui bagian tubuh penutur.

Lawan tutur orang tua adalah Jihan (anak-anak). Oleh karena itu, dituntut orang tua untuk dapat bertutur dengan bahasa yang halus 
mempertimbangkan psikologis anak. Sedangkan isyarat kinestetik yang mengikuti tuturan biasanya sebatas pada eskpresi wajah. Apabila terdapat anak yang melakukan kesalahan atau tidak menurut, orang tua Jihan menunjukkan ekspresi wajah marah atau jengkel, Jihan sudah bisa memahami dan mengikutinya.

4. Penggunaan ungkapan-ungkapan penanda kesantunan Secara linguistik, kesantunan dalam pemakaian tuturan imperatif bahasa Indonesia sangat ditentukan oleh muncul atau tidak munculnya ungkapan- ungkapan penanda kesantunan. Dari bermacam-macam penanda kesantunan itu dapat

\section{HASIL PELAKSANAAN}

\section{a. Deskripsi Pelaksanaan}

Dalam pengabdian ini kami mulai dari membahas tentang etika berbicara dalam keluarga, dilengkapi dengan tanya jawab dari para pendengar Radio 93,0 Respon FM warga Kasang Kab. Padang Pariaman. Di dalam pelaksanaannya kami dibantu oleh penyiar dari Radio 93,0 Respon FM. Setelah penjelasan dari para dosen dan lanjut pada sesi pertanyaaan secara langsung dihubungi oleh beberapa disebutkan beberapa sebagai berikut: tolong, mohon, silakan, mari, ayo, biar, coba, harap, hendaknya, hendaklah, -lah, sudi kiranya, sudilah apalah kiranya. Apabila mengacu pada penanda kesantunan yang digunakan di lingkungan keluarga di antaranya: tolong, mari, ayo, dan coba.

Intinya adalah komunikasi di rumah tangga harus lemah lembut, menyenangkan dengan sendirinya indahnya sopan santun dirasa di rumah terjaga apabila komunikasi terjaga baik, merupakan salah satu resep rumah tangga bahagia, inilah yang di rangkum dalam hadits Nabi SAW," Rumahku adalah Surga bagi $\mathrm{ku}$ ".

warga Kasang Kab. Padang Pariaman.

Kegiatan Pengabdian kepada masyarakat yang sudah dilakukan langsung melalui Radio 93,0 Respon FM dengan tema Etika Berbicara dalam Keluarga yang diadakan pada Hari dan Tanggal : Sabtu / 25 Juli 2020, Waktu : 08.00 - 12.00 WIB, Lokasi : Kantor Radio 93,0 Respon FM. Selain itu kegiatan pengabdian dilakukan dengan rincian acara sebagai berikut:

\begin{tabular}{|l|l|l|l|}
\hline No & Waktu & Kegiatan & Pemateri \\
\hline 1 & $08.00-08.30$ & Pembukaan & \\
& & 1. Penyiar dan Kru & Yulia \\
& & dari Pihak & Dini P Susanti, \\
& & Radio 93,0 & M.Pd \\
& & Respon FM & \\
& & 2. Kata sambutan & \\
& & dari tim & \\
\hline 2 & $08.30-09.30$ & Materi I Etika & Firdaus, M.H.I \\
\hline
\end{tabular}




\begin{tabular}{|c|c|c|c|}
\hline 3 & $09.30-10.30$ & Materi II Keluarga & $\begin{array}{l}\text { Dr. Syaflin Halim, } \\
\text { M.A \& Vini Wela } \\
\text { Septiana, M.Pd }\end{array}$ \\
\hline 4 & $10.30-11.30$ & $\begin{array}{l}\text { Materi III } \\
\text { Etika Berbicara } \\
\text { dalam Keluarga }\end{array}$ & $\begin{array}{l}\text { Ismail Syakban, } \\
\text { M.Pd.I \& } \\
\text { Thaheransyah, } \\
\text { S.Sos, I, MA }\end{array}$ \\
\hline 5 & $11.30-12.00$ & Penutupan & \\
\hline
\end{tabular}

\section{b. Pihak-Pihak yang Terlibat}

Pihak yang terlibat dalam kegiatan pengabdian masyarakat yang dilakukan ini secara teknis melibatkan kerjasama instansi Fakultas Agama Islam dengan
Radio 93,0 Respon FM, pengabdian ini dilaksanakan beberapa orang pelaksana dari dosen dan mahasiswa FAI UMSB sebagai berikut:

\begin{tabular}{|c|c|c|}
\hline Nama lengkap & : Firdaus M.H.I/Ketua & \\
\hline NIP/NIK/NIDN & : 1027026802 & \\
\hline Jabatan Fungsional & : Lektor & \\
\hline Pangkat Golongan & : Penata Muda Tk.I/IIIc Fakultas/Prodi & : FAI/ Ahwal Al- \\
\hline \multicolumn{3}{|c|}{ Syakhshiyah Bidang Keahlian: Hukum Islam } \\
\hline Nama lengkap & : Dini Susanti, M.Pd & \\
\hline NIP/NIK/NIDN & : 1015018604 & \\
\hline Jabatan Fungsional & : Lektor & \\
\hline Pangkat Golongan & : Penata Muda Tk.I/IIIc Fakultas/Prodi & : FAI/ PGMI \\
\hline Bidang Keahlian & : Pendidikan Guru MI & \\
\hline Nama lengkap & : Vini Wela Septiana, M.Pd & \\
\hline NIP/NIK/NIDN & : 1027098603 & \\
\hline Jabatan Fungsional & : Lektor & \\
\hline Pangkat Golongan & : Penata Muda Tk.I/IIIc & \\
\hline Fakultas/Prodi & : FAI/ PGMI & \\
\hline Bidang Keahlian & : Pendidikan Guru MI & \\
\hline Nama lengkap & : Dr. Syaflin Halim, M.A & \\
\hline NIP/NIK/NIDN & $: 1026048305$ & \\
\hline Jabatan Fungsional & : Lektor & \\
\hline Pangkat Golongan & : Penata Muda Tk.I/IIIc Fakultas/Prodi & : FAI/ AS \\
\hline Bidang Keahlian & : Hukum Islam & \\
\hline
\end{tabular}




\begin{tabular}{|c|c|c|}
\hline Nama lengkap & : Thaheransyah & \\
\hline NIP/NIK/NIDN & : 1016028702 & \\
\hline Jabatan Fungsional & : Tenaga Pengajar Pangkat Golongan & : Penata Muda Tk.I \\
\hline / IIIB Fakultas/Prodi & : FAI/ BPI & \\
\hline Bidang Keahlian & : Dakwah dan Pengembangan Masyarakat & \\
\hline Nama lengkap & : Ismail Syakban & \\
\hline NIP/NIK/NIDN & $: 1014039001$ & \\
\hline Jabatan Fungsional & : Asisten Ahli & \\
\hline Pangkat Golongan & : Penata Muda Tk.I/IIIc Fakultas/Prodi & :FAI/ \\
\hline Bidang Keahlian & : Pemikiran Pendidikan Islam & \\
\hline Nama lengkap & : Rahmad Illahi & \\
\hline NIM & : 1706002014002 & \\
\hline Jabatan & : Mahasiswa PGMI & \\
\hline Fakultas/Prodi & : FAI/ PGMI & \\
\hline
\end{tabular}

\section{c. Keuangan}

Laporan Keuangan Pelaksanaan Pengabdian Masyarakat

\begin{tabular}{|l|l|l|l|l|l|l|}
\hline No & Hari/Tangga & Uraian & Debit & Kredit & Ket \\
\hline 1 & $\begin{array}{l}\text { Selasa } 30 \\
\text { Juni }\end{array}$ & Sumbangan Dosen & Rp. 2.150.000 & & \\
\hline \multicolumn{2}{|l|}{ UANG KELUAR } \\
\hline 1 & Selasa 7 Juli & Rapat Persiapan & & Rp. 150.000 & \\
\hline 2 & Rabu 8 Juli & ATK & & Rp. 100.000 & \\
\hline 3 & Sabtu 11 Juli & Rapat Pematangan & & Rp. 200.000 & \\
\hline 4 & Selasa 21 Juli & Spanduk & & Rp. 50.000 & \\
\hline 5 & Sabtu 25 Juli & Pelaksanaan & & Rp. 1.500.000 & \\
\hline 6 & $\begin{array}{l}\text { Selasa 11 } \\
\text { Agustus }\end{array}$ & $\begin{array}{l}\text { Penertiban Luaran } \\
\text { Berita Online }\end{array}$ & & Rp. 150.000 & \\
\hline Jumlah & & Rp.2.150.000 & Rp.2.150.000 & \\
\hline Sisa & & & & \\
\hline
\end{tabular}




\section{HASIL PELAKSANAAN}

Pelaksaan pengabdian kepada masyarakat yang telah dilaksanakan oleh tim pengabdian telah mendapatkan respon positif baik oleh pihak Radio 93,0 Respon FM. Berawal dari program ini akan dilaksanakan dengan pengurus terdapat kesepakatan yang sangat besar dengan melakukan kordinasi secara terus menerus untuk mendapatkan waktu dan kesempatan untuk melakukan pelaksanaan pengabdian ini bisa dilakukan, dengan kordinasi tersebut menjadikan kegiatan ini bisa laksanakan dengan baik.

Dari beberapa hasil tanya jawab dengan warga / masyarakat secara langsung, umumnya mereka merasakan termotivasi dan semangat yang tinggi dalam melakukan kegiatan ini. Metode yang dilakukan pada pengabdian ini berbentuk penyampaian materi kemudian langsung tanya jawab.

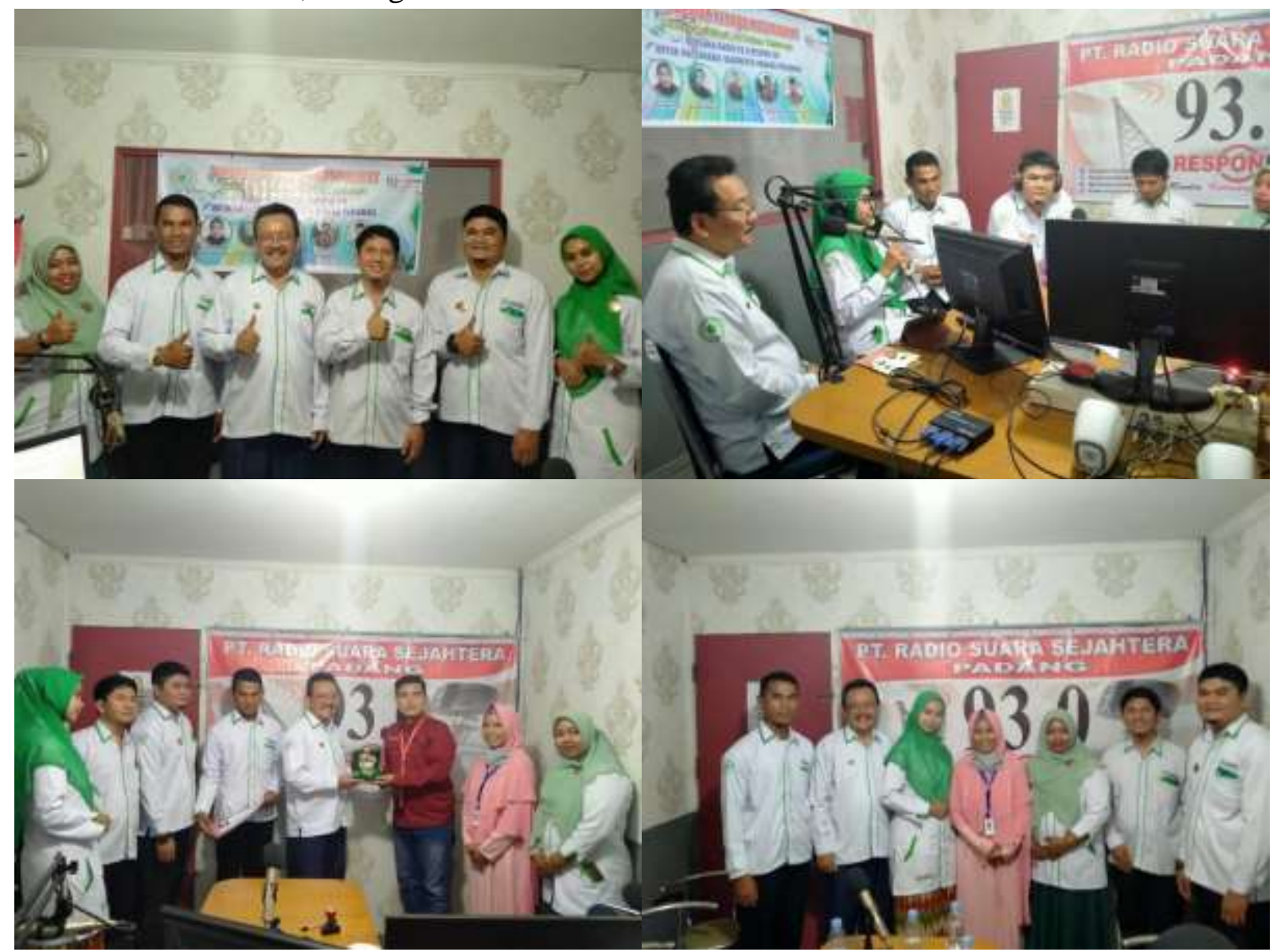




\section{PENUTUP}

\section{a. Kesimpulan}

Pembinaan tentang etika berbicara dalam keluarga yang dilakukan sebagai pengabdian masyarakat memperoleh antusias yang sangat tinggi, baik dari kru radio Radio 93,0 Respon FM dan masyarakat sekitar Kasang Kab. Padang Pariaman. Mulai dari awal kegiatan sampai dengan tanya jawab secara langsung. Dengan telah dilakukannya pengabdian masyarakat ini warga masyarakat Kasang dan sekitranya merasa bertambah wawasannya dan merasa diperhatikan oleh FAI UMSB yang terkait mengenai pembinaan tentang etika berbicara dalam keluarga.

\section{b. Saran}

Pembinaan etika berbicara dalam keluarga untuk warga Kasang dan sekitarnya sangat penting dilakukan untuk membantu pemahaman tentang komunikasi sesuai dengan syariat dan sunnah yang diajarkan rasulullah SAW. Untuk itu diharapkan kepada semua peserta pengabdian bersungguh- sungguh dalam etika berbicara dalam keluarga serta melaksanakan praktek (berbicara) yang telah dilakukan di lingkuangan kelurga. 